УДК 661.531

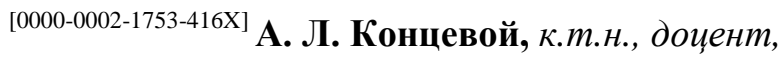
e-mail: kontsev@xtf.kpi.ua

${ }^{[0000-0002-4523-2273]}$ С. А. Концевой, к.т.н., доцент

e-mail: serkon157@ukr.net

Київський політехнічний інститут імені Ігоря Сікорського

проспект Перемоги, 37, м. Київ, 03056, Україна

\title{
МОДЕЛЮВАННЯ ДВОПОТОКОВОЇ РЕГЕНЕРАЦІЇ РОЗЧИНУ МОНОЕТАНОЛАМІНУ
}

Надано алгоритм розрахунку матеріального і теплового балансів регенеращії відпращьованого розчину в середовищі Excеl з варіюванням концентрачійних параметрів по розчину.

Апроксимовано залежності рівноважного париіального тиску $\mathrm{CO}_{2}$ над 20 \%-ним розчином моноетаноламіну залежно від ступеня карбонізації та температури регенерачії. Числовим інтегруванням розраховано двосекційний тарілчастий регенератор.

Ключові слова: технологічний газ, оксид карбону (IV), моноетаноламін, кінетика і термодинаміка десорбиії, тарілчастий десорбер.

Вступ. Важливою стадією виробництва аміаку є очищення технологічного газу від оксиду карбону (IV) абсорбційними методами, насамперед, розчином моноетаноламіну або активованим гарячим розчином поташу. Особливості хімізму, апаратурного оформлення і показники очищення наведено в роботах [1-3]. Результати моделювання очищення газу активованим розчином метилдіетаноламіну нами надано в статтях $[4,5]$.

Високопродуктивні схеми виробництва аміаку використовують двопотокове очищення газу від $\mathrm{CO}_{2}$ розчином моноетаноламіну (MEA) 3 регенерацією відпрацьованого розчину у двох паралельно працюючих регенераторах-рекуператорах, 3 яких відводяться на абсорбцію два потоки - тонко і грубо регенерованого розчинів [6-8]. Стаття є логічним продовженням запропонованого нами алгоритму розрахунку абсорбційного очищення технологічного газу [9]. Регенерація відпрацьованого розчину MEA базується на перебігу наступних реакцій:

$$
\begin{gathered}
\left(\mathrm{RNH}_{3}\right)_{2} \mathrm{CO}_{3} \leftrightarrow \mathrm{CO}_{2}+2 \mathrm{RNH}_{2}+\mathrm{H}_{2} \mathrm{O}, \\
2 \mathrm{RNH}_{3} \mathrm{HCO}_{3} \leftrightarrow \mathrm{CO}_{2}+\left(\mathrm{RNH}_{3}\right)_{2} \mathrm{CO}_{3}+\mathrm{H}_{2} \mathrm{O},
\end{gathered}
$$
де $\mathrm{R}-\mathrm{HOCH}_{2} \mathrm{CH}_{2}$.

Карбонат і гідрокарбонат моноетаноламонію при підвищенні температури і зменшенні тиску легко дисоціюються, що дає змогу проводити глибоку регенерацію поглинального розчину.

Мета роботи: виконання матеріальних, теплових i конструктивних розрахунків за власним алгоритмом 3 його реалізацією в се- редовищі Excel. Змінними параметрами, що впливають на технологічний режим, $є$ температура, тиск, ступінь карбонізації розчину у різних точках десорбера.

Вихідні дані. Для двопотокової схеми очищення розраховано матеріальні, теплові баланси десорбції та тарілчастий десорбер 3 наступними вихідними даними. Продуктивність за аміаком - 1360 т/добу. Температура газу на виході із сепаратора $\mathrm{t}=40{ }^{\circ} \mathrm{C}$; тиск насиченої пари при $\mathrm{t}=40{ }^{\circ} \mathrm{C}_{2}{ }^{*}=0,07245$ aтм; тиск на виході із сепаратора $\mathrm{P}_{2}=1,7$ атм. Температура газу на виході 3 регенератора $\mathrm{t}=70{ }^{\circ} \mathrm{C}$; тиск насиченої пари при $\mathrm{t}=70{ }^{\circ} \mathrm{C}$ $\mathrm{P}_{3}{ }^{*}=0,3$ атм; тиск на виході $з$ регенератора $\mathrm{P}_{3}=1,7$ aтм.

Результати. Матеріальний баланс. Склад сухого газу на виході із сепаратора, в який він надходить 3 верхньої частини регенератора, визначається за даними матеріального балансу абсорбції [9] (таблиця 1): всі розчинені компоненти десорбуються при регенерації (враховується факт того, що частина $\mathrm{CO}_{2}$ завжди залишається у розчині з відповідним ступенем карбонізації). Вологість газу на виході із сепаратора, частка:

$$
\begin{aligned}
& \mathrm{N}_{2}=\mathrm{P}_{2}{ }^{*} / \mathrm{P}_{2}=\mathrm{V}_{2} /\left(\mathrm{V}_{2}+\mathrm{Vg}\right) ; \\
& \mathrm{N}_{2}=0,07245 / 1,7=0,0426,
\end{aligned}
$$

звідки при відомому значенні витрати сухого газу $\left(\mathrm{Vg}=36211,47 \mathrm{~m}^{3} /\right.$ год.) визначаємо витрату водяної пари на виході 3 сепаратора, $\mathrm{M}^{3} /$ год. (таблиця 2):

$$
\mathrm{V}_{2}=\mathrm{Vg} \cdot \mathrm{N}_{2} /\left(1-\mathrm{N}_{2}\right), \mathrm{V}_{2}=1611,95 \text {. }
$$


Таблиця 1 - Склад сухого газу на виході із сепаратора

\begin{tabular}{|c|c|c|c|c|}
\hline Компонент & нм$^{3} /$ год. & \% об. & кг/год. & \% мас. \\
\hline $\mathrm{H}_{2}$ & 380,03 & 1,05 & 33,93 & 0,048 \\
\hline $\mathrm{N}_{2}$ & 76,89 & 0,21 & 96,12 & 0,137 \\
\hline $\mathrm{CO}_{2}$ & 35746,05 & 98,71 & 70212,56 & 99,801 \\
\hline $\mathrm{CO}$ & 3,08 & 0,01 & 3,85 & 0,005 \\
\hline $\mathrm{Ar}$ & 2,41 & 0,01 & 4,30 & 0,006 \\
\hline $\mathrm{CH}_{4}$ & 3,00 & 0,01 & 2,15 & 0,003 \\
\hline Всього & 36211,47 & 100,00 & 70352,91 & 100,00 \\
\hline
\end{tabular}

Таблиця 2 - Склад вологого газу на виході із сепаратора

\begin{tabular}{|c|c|c|c|c|}
\hline Компонент: & м $^{3}$ год. & \% об. & кг/год. & \% мас. \\
\hline $\mathrm{H}_{2}$ & 380,03 & 1,00 & 33,93 & 0,047 \\
\hline $\mathrm{N}_{2}$ & 76,89 & 0,20 & 96,12 & 0,134 \\
\hline $\mathrm{CO}_{2}$ & 35746,05 & 94,51 & 70212,56 & 97,996 \\
\hline $\mathrm{CO}$ & 3,08 & 0,01 & 3,85 & 0,005 \\
\hline $\mathrm{Ar}$ & 2,41 & 0,01 & 4,30 & 0,006 \\
\hline $\mathrm{CH}_{4}$ & 3,00 & 0,01 & 2,15 & 0,003 \\
\hline $\mathrm{H}_{2} \mathrm{O}$ & 1611,95 & 4,26 & 1295,31 & 1,808 \\
\hline Всього: & 37823,42 & 100,00 & 71648,22 & 100,00 \\
\hline
\end{tabular}

Відносна вологість газу на виході з регенератора, частка:

$$
\begin{gathered}
\mathrm{N}_{3}=\mathrm{P}_{3}{ }^{*} / \mathrm{P}_{3}=\mathrm{V}_{3} /\left(\mathrm{V}_{3}+\mathrm{Vg}\right) ; \\
\mathrm{N}_{3}=0,3 / 1,7=0,1765,
\end{gathered}
$$

звідки визначаємо витрату води на підживлення для компенсації виносу водяної пари, $\mathrm{M}^{3} /$ год:

$$
\begin{gathered}
\mathrm{V}_{3}=\mathrm{Vg} \cdot \mathrm{N}_{3} /\left(1-\mathrm{N}_{3}\right), \\
\mathrm{V}_{3}=7759,29 .
\end{gathered}
$$

Результати розрахунку надано у таблиці 3

Об'єм (м³/год. водяної пари) та маса (кг/год.) флегми, відповідно:

$$
\begin{gathered}
\mathrm{V}\left(\mathrm{H}_{2} \mathrm{O}\right)=\mathrm{V}_{3}-\mathrm{V}_{2} ; \\
\mathrm{V}\left(\mathrm{H}_{2} \mathrm{O}\right)=7759.29-1611,95=6147,34 . \\
\mathrm{m}_{\text {флегми }}=\mathrm{m}_{3}-\mathrm{m}_{2} ; \\
\mathrm{m}_{\text {флегми }}=6235,14-1295,31=4939,83 .
\end{gathered}
$$

Таблиця 3 - Склад вологого газу на виході 3 регенератора

\begin{tabular}{|c|c|c|c|c|}
\hline Компонент: & м $^{3} /$ год. & \% об. & кг/год. & \% мас. \\
\hline $\mathrm{H}_{2}$ & 380,04 & 0,864 & 33,93 & 0,044 \\
\hline $\mathrm{N}_{2}$ & 76,90 & 0,175 & 96,12 & 0,126 \\
\hline $\mathrm{CO}_{2}$ & 35744,57 & 81,294 & 70212,56 & 91,676 \\
\hline $\mathrm{CO}$ & 3,08 & 0,007 & 3,85 & 0,005 \\
\hline $\mathrm{Ar}$ & 2,41 & 0,005 & 4,30 & 0,006 \\
\hline $\mathrm{CH}_{4}$ & 3,00 & 0,007 & 2,15 & 0,003 \\
\hline $\mathrm{H}_{2} \mathrm{O}$ & 7759,29 & 17,647 & 6235,14 & 8,141 \\
\hline Всього: & 43969,29 & 100 & 76588,0468 & 100 \\
\hline
\end{tabular}

Тепловий баланс. Підігрів розчину проводять за рахунок теплоти неочищеного конвертованого газу, що подається у кип'ятильники MEA. Мета розрахунку полягає у визначенні теплоти $\mathrm{Q}_{\text {кг }}$, що надходить 3 конвертованим газом. Вихідні дані: витрати, кг/год., відпрацьованого розчину у регенератор m(MEA) $)_{\text {-ну }}=1193713$ [9, таблиця 5]; витрата двох потоків розчину 3 регенератора m(MEA) ${ }_{\text {p-ну }}=\mathrm{L}_{2}+\mathrm{L}=1123717,1$ [9]; теплоємність розчину MEA на вході $\mathrm{Cp}_{\mathrm{вx}}=4,304$ кДж/(кг $\left.{ }^{\circ} \mathrm{C}\right)$; теплоємність розчи- 
ну MEA на виході $\mathrm{Cp}_{\text {вих }}=4$ кДж/(кг $\left.{ }^{\circ} \mathrm{C}\right)$; теплоємність вологого газу на виході з регенератора $\mathrm{Cp}_{3}=35$ кДж/(кмоль $\left.{ }^{\circ} \mathrm{C}\right)$; температура відпрацьованого розчину МЕА на вході в регенератор $\mathrm{t}_{\mathrm{Bx}}=62.2^{\circ} \mathrm{C}$; температура регенерованих розчинів MEA і вологого газу на виході 3 регенератора, ${ }^{\circ} \mathrm{C}, \mathrm{t}_{\text {вих }}=70$; температура конденсату (флегми) на виході сепаратора, ${ }^{\circ} \mathrm{C}$, $\mathrm{t}_{4}=40$; теплота десорбції $\mathrm{CO}_{2}$, кДж/кг $\mathrm{CO}_{2}$, $\mathrm{Q}_{\mathrm{CO} 2}=1507$; теплота випаровування води в регенераторі, кДж/кг, $\mathrm{Q}_{\text {вип }}=2200$; втрати теплоти, частка, $\mathrm{W}_{\text {втрат }}=0,05$.

Рівняння теплового балансу:

$\mathrm{Q}_{1}+\mathrm{Q}_{4}+\mathrm{Q}_{\text {кг }}=\mathrm{Q}_{3}+\mathrm{Q}_{5}+\mathrm{Q}_{6}+\mathrm{Q}_{\text {втрат }}$.

Основними статтями приходу теплового балансу є:

- теплота, що вноситься 3 розчином MEA, кДж/год:

$$
\begin{aligned}
& \mathrm{Q}_{1}=\mathrm{m}(\mathrm{MEA})_{\mathrm{p}-\mathrm{Hy}} \cdot \mathrm{t}_{\mathrm{Bx}} \cdot \mathrm{Cp}_{\mathrm{Bx}} ; \\
& \mathrm{Q}_{1}=1193713 \cdot 62.2 \cdot 4,304=319567475 \text {; } \\
& \mathrm{Q}_{4}=\mathrm{m}_{\text {флегми }} \cdot \mathrm{t}_{4} \cdot \mathrm{Cp}_{\text {води }} \text {; } \\
& \mathrm{Q}_{4}=5761,32 \cdot 40 \cdot 4,19=965597 \text {, }
\end{aligned}
$$

кДж/год:

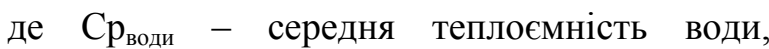
кДж/(кг $\left.{ }^{\circ} \mathrm{C}\right): \mathrm{Cp}_{\text {води }}=4,19$;

- теплота, що вноситься 3 теплоносієм (конвертованим газом), кДж/год:

$\mathrm{Q}_{\mathrm{Kт}}=\left(\mathrm{Q}_{3}+\mathrm{Q}_{5}+\mathrm{Q}_{6}-\left(1-\mathrm{W}_{\text {втрат }}\right) \cdot \mathrm{Q}_{1}-\right.$ $\left.-\left(1-\mathrm{W}_{\text {втрат }}\right) \cdot \mathrm{Q}_{4}\right) /\left(1-\mathrm{W}_{\text {втрат }}\right)$.

Основними статтями витрат теплового балансу є:

- теплота, що виноситься вологим газом з регенератора, кДж/год:

$$
\begin{gathered}
\mathrm{Q}_{3}=\Sigma \mathrm{V} \cdot \mathrm{t}_{\text {вих }} \cdot \mathrm{Cp}_{3} / 22,4 ; \\
\mathrm{Q}_{3}=44993,06 \cdot 70 \cdot 35 / 22,4=4921116 ; \\
\text { - теплота реакції десорбції і випарову- }
\end{gathered}
$$
вання, кДж/год:

$$
\begin{gathered}
\mathrm{Q}_{5}=\mathrm{QCO}_{2} \cdot \mathrm{m}\left(\mathrm{CO}_{2}\right)_{\text {дес }}+\mathrm{Q}_{\text {вип }} \cdot \mathrm{m}_{\text {пари }} ; \\
\mathrm{Q}_{5}=1507 \cdot 70212,56+2200 \cdot 7056,63= \\
=121334921 ;
\end{gathered}
$$

- теплота, що виноситься регенерованим розчином MEA (прийнято, що при однаковій температурі тонко- і грубо регенерований розчини мають приблизно ту саму теплоємність), кДж/год:

$$
\begin{gathered}
\mathrm{Q}_{6}=\mathrm{m}(\mathrm{MEA}) * \text { p-ну } \\
\mathrm{Q}_{6}=1123717,1 \cdot 70 \cdot 4=314660369 .
\end{gathered}
$$

Отже, $з$ рівняння (1):

$\mathrm{Q}_{\text {кг }}=143589461$ кДж/год.

Втрати теплоти у довкілля, кДж/год:

$\mathrm{Q}_{\text {втрат }}=\left(\mathrm{Q}_{1}+\mathrm{Q}_{4}+\mathrm{Q}_{\text {кг }}\right) \cdot \mathrm{W}_{\text {втрат }}=23206126,6$.

Питома витрата теплоти на $1 \mathrm{~m}^{3} \mathrm{CO}_{2}$, МДж/ $\mathrm{M}^{3} \mathrm{CO}_{2}$ :

$$
\begin{gathered}
\mathrm{q}_{\text {пит }}=\mathrm{Q}_{\text {кг }} /\left(\mathrm{V}\left(\mathrm{CO}_{2}\right)_{\text {дес }} \cdot 1000\right) ; \\
\mathrm{q}_{\text {пит }}=143589461 /(35746,05 \cdot 1000)=4,02 .
\end{gathered}
$$

Питома витрата теплоти на 1 т аміаку, МДж/т:

$$
\mathrm{q}_{\text {пит }}=143589461 / 56,67=2533,8 .
$$

Порівняємо отримані дані за питомою витратою теплоти 3 літературними. Згідно 3

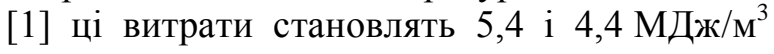
$\mathrm{CO}_{2}$ для багатопотокової схеми і схеми 3 регенератором-рекуператором, відповідно. Питомі витрати теплоти на 1 т аміаку дорівнюють 2976 МДж/т [5]. Таким чином, розрахункові дані мають однаковий порядок 3 промисловими.

Кінетичний розрахунок регенератора. Розрахунок тарілчастого десорбера базується на обробці рівноважних і практичних даних 3 визначенням кількості теоретичних тарілок $\mathrm{Nt}$ числовим інтегруванням виразу

$$
\mathrm{Nt}=\int \mathrm{dP} /\left(\mathrm{P}^{*}-\mathrm{P}\right),
$$

де $\mathrm{P}$ i $\mathrm{P} *$ - робочий і рівноважний тиск $\mathrm{CO}_{2}$, кПа. Табличні довідкові значення рівноважного тиску $\mathrm{CO}_{2}$ над $20 \%$-ним розчином MEA залежно від температури розчину $\mathrm{T}$ та ступеня карбонізації $\alpha$ [10] апроксимовані нами наступним чином. Для більшої точності апроксимації розбиваємо довідкові дані на дві ділянки за ступенем карбонізації. В результаті було отримані рівняння регресії для розрахунку $\mathrm{P}^{*}$, кПа:

для $\alpha>0,42$

$$
\mathrm{P}^{*}=\exp (25,85696-5292,15 / \mathrm{T}+
$$

$\left.+8,977071 * \operatorname{Ln}(\alpha)-2,98796^{*} \alpha^{\wedge} 2\right)$,

при цьому середнє відхилення розрахункових даних від табличних становить 9,8\%;

для $\alpha<0,42$

$$
\begin{aligned}
& \mathrm{P}^{*}=\exp (30,06715-9904,45 / \mathrm{T}+ \\
& \left.+2,024316^{*} \operatorname{Ln}(\alpha)+7,52984^{*} \alpha^{\wedge} 2\right),
\end{aligned}
$$

середнє відхилення розрахункових даних від табличних становить $4,76 \%$.

Парціальний тиск $\mathrm{CO}_{2}$ у верхній частині регенератора, кПа:

$$
\mathrm{P}^{\mathrm{B}}=\mathrm{P}_{3} \cdot \mathrm{N}\left(\mathrm{CO}_{2}\right) \cdot 101325 / 1000 / 100 ;
$$

$\mathrm{P}^{\mathrm{B}}=1,7 \cdot 81,294 \cdot 101325 / 1000 / 100=140,032$, 
де $\mathrm{N}\left(\mathrm{CO}_{2}\right)$ - вміст $\mathrm{CO}_{2}$ у вологому газі на виході з регенератора (з верхньої тарілки), \% об., $\mathrm{N}\left(\mathrm{CO}_{2}\right)=81,294$ (див. таблицю 3).

2. Коефіцієнт перерахунку рівноважного тиску у робочий:

$$
\begin{gathered}
\mathrm{K}_{\text {пер }}=\mathrm{P}^{\mathrm{B}} / \mathrm{P}^{\mathrm{B}} \mathrm{p} ; \\
\mathrm{K}_{\text {пер }}=140,032 / 242,63=0,5771,
\end{gathered}
$$

де $\mathrm{P}^{\mathrm{B}} \mathrm{p}=242,631$ - розрахункове значення рівноважного тиску $\mathrm{CO}_{2}$ над розчином MEA за рівнянням (2) при ступені карбонізації $\alpha_{1}=0,67$ кмоль $\mathrm{CO}_{2}$ /кмоль MEA і температурі на верхній тарілці 343 К. Зауважимо, що саме для верхньої тарілки відомі і рівноважні, і робочі парціальні тиски $\mathrm{CO}_{2}$ над розчином MEA. Завдяки коефіцієнту $\mathrm{K}_{\text {пер }}$ буде здійснюватися розрахунок робочого парціального тиску на інших тарілках. Звісно, це певне наближення, але, при відсутності даних 3 концентрації $\mathrm{CO}_{2}$ у парогазовій суміші по висоті регенератора, нами прийнято саме таке рішення.

Buxidнi данi. Тиск вологого газу на виході 3 регенератора $\mathrm{P}_{3}=1,7$ атм. Ступінь карбонізації розчину МЕА, кмоль/кмоль МЕА: відпрацьованого розчину на вході у регенератор $\alpha_{0}=0,67$; грубо регенерованого розчину $\alpha_{1}=0,35$; тонко регенерованого розчину $\alpha_{2}=0,1$. Температура: на верхній тарілці $\mathrm{T}_{0}=343 \mathrm{~K}$ (за рахунок нагріву відпрацьованого розчину після вводу у регенератор 3 335,2 К); виводу грубо регенерованого розчину $\mathrm{T}_{1}=388 \mathrm{~K}$; виводу тонко регенерованого розчину $\mathrm{T}_{2}=398 \mathrm{~K}$ (обидва потоки подаються на рекуперацію теплоти у верхню частину регенератора). Кількість кроків інтегрування $\mathrm{n}=100$.

Покроковий алгоритм розрахунку. Зміна ступеня карбонізації на один крок інтегрування

$$
\mathrm{d} \alpha=\left(\alpha_{0}-\alpha_{2}\right) / \mathrm{n}=(0,67-0,1) / 100=0,0057 .
$$

Зміна температури розчину MEA на один крок інтегрування (від $\alpha_{0}=0,67$ до $\alpha_{1}=0,35$ досягається на 56-му кроці інтегрування)

$$
\mathrm{dT}=\left(\mathrm{T}_{1}-\mathrm{T}_{0}\right) / 56=(388-343) / 56=0,8036 .
$$

Зміна температури розчину MEA у нижній частині регенератора на один крок інтегрування (від $\alpha_{1}=0,35$ до $\alpha_{2}=01$ досягається на 100-му кроці інтегрування)

$$
\begin{gathered}
\mathrm{dT}=(\mathrm{T} 2-\mathrm{T} 1) / 43=(398-388) /(100-56)= \\
=0,2273 .
\end{gathered}
$$

Температура розчину MEA, $\mathrm{K}, \mathrm{T}_{\mathrm{i}}=\mathrm{T}_{\mathrm{i}-1}+\mathrm{dT}$.
Ступінь карбонізації розчину MEA, кмоль/кмоль MEA, $\alpha_{\mathrm{i}}=\alpha_{\mathrm{i}-1}+\mathrm{d} \alpha$.

Рівноважний тиск $\mathrm{CO}_{2}$ над розчином MEA P* у регенераторі від $\alpha_{0}=0,67$ до $\alpha=0,42$ визначається за рівнянням (2), а від $\alpha=0,42$ до $\alpha_{2}=0,1$ - за рівнянням (3).

Тиск $\mathrm{CO}_{2}$ над розчином МЕА, кПа,

$$
\mathrm{P}_{\mathrm{i}}=\mathrm{K} \text { пер } \cdot \mathrm{P}^{*}{ }_{\mathrm{i}} \text {. }
$$

Крок інтегрування за парціальним тиском $\mathrm{CO}_{2} \Delta \mathrm{P}_{\mathrm{i}}=\left(\mathrm{P}_{\mathrm{i}-1}-\mathrm{P}_{\mathrm{i}}\right)$.

Необхідна кількість теоретичних тарілок на один крок інтегрування

$$
\mathrm{Nt}_{\mathrm{i}}=\Delta \mathrm{P} /\left(\mathrm{P}_{\mathrm{i}}{ }-\mathrm{P}_{\mathrm{i}}\right) .
$$

Коефіцієнт корисної дії тарілки регенератора залежно від ступеня карбонізації за даними [6], частка:

$$
\eta_{\mathrm{i}}=\left(7,48+57,49 * \alpha_{\mathrm{i}}-31 * \alpha_{\mathrm{i}}^{\wedge} 2\right) / 100 \text {. }
$$

Враховуючи ККД тарілки, необхідна кількість тарілок на один крок інтегрування

$$
\mathrm{Npr}_{\mathrm{i}}=\mathrm{Nt}_{\mathrm{i}} / \eta_{\mathrm{i}} \text {. }
$$

Практична кількість тарілок

$$
\mathrm{Npr}=\sum \mathrm{Npr}_{\mathrm{i}} .
$$

За даними таблиці 4 кількість тарілок у верхній частині регенератора становить $\mathrm{Npr}=10,67$, у нижній $-22,55$; загальна кількість дорівнює 33,22. У промисловості працюють регенератори-рекуператори, які мають 31 тарілку (22 тарілки у верхній частині і 9 тарілок у нижній). Для гарантованої якості регенерації використовують два апарати. Розбіжність розподілу тарілок між верхньою і нижньою частинами регенератора за нашим алгоритмом i промисловими даними може бути пояснена припущенням про лінійний профіль температур по висоті верхньої частини апарату (одночасна регенерація розчину i рекуперація теплоти) і застосуванням коефіцієнта К тора. Зауважимо також, що у нижню частину надходить половина всього розчину MEA, що в кінетичному розрахунку не враховується.

Висновки. Використання запропонованого методу розрахунку буде корисним для багатоваріантного аналізу роботи діючих виробництв, а також для студентів при навчальному проектуванні процесу регенерації відпрацьованого розчину МЕА. Алгоритм може бути легко перероблений для розрахунку більш простої однопотокової регенерації, яка розповсюджена на заводах зв'язаного азоту України. 
Таблиця 4 - Розрахунок тарілчастого десорбера (фрагмент)

\begin{tabular}{|c|c|c|c|c|c|c|c|c|}
\hline № & $\alpha$ & $\mathrm{T}$ & $\mathrm{P}^{*}$ & $\mathrm{P}$ & $\Delta \mathrm{P}$ & $\mathrm{Nt}$ & $\eta$ & $\mathrm{Npr}$ \\
\hline 0 & 0,6700 & 343,000 & 242,629 & 140,032 & & & & \\
\hline 1 & 0,6643 & 343,804 & 238,322 & 134,417 & 2,429 & 0,025 & 0,3199 & 0,077 \\
\hline 2 & 0,6586 & 344,607 & 233,852 & 131,896 & 2,521 & 0,026 & 0,3189 & 0,082 \\
\hline 54 & 0,362 & 386,393 & 28,964 & 16,717 & 0,160 & 0,013 & 0,2424 & 0,054 \\
\hline 55 & 0,356 & 387,196 & 28,683 & 16,554 & 0,162 & 0,013 & 0,2404 & 0,056 \\
\hline \multirow[t]{2}{*}{56} & 0,351 & 388,000 & 28,397 & 16,389 & 0,165 & 0,014 & 0,2383 & 0,058 \\
\hline & & & & & $\sum$ Nверх & 3,013 & & 10,67 \\
\hline 57 & 0,345 & 388,227 & 27,064 & 15,620 & 0,769 & 0,067 & 0,2363 & 0,285 \\
\hline 58 & 0,339 & 388,455 & 25,792 & 14,885 & 0,735 & 0,067 & 0,2342 & 0,288 \\
\hline 59 & 0,334 & 388,682 & 24,576 & 14,184 & 0,701 & 0,067 & 0,2321 & 0,291 \\
\hline 98 & 0,111 & 397,545 & 2,234 & 1,290 & 0,131 & 0,138 & 0,1350 & 1,025 \\
\hline 99 & 0,106 & 397,773 & 2,019 & 1,165 & 0,124 & 0,146 & 0,1321 & 1,103 \\
\hline 100 & 0,100 & 398,000 & 1,814 & 1,047 & 0,118 & 0,154 & 0,1292 & 1,191 \\
\hline & & & & & $\sum$ Nнижн & 3,882 & & 22,55 \\
\hline
\end{tabular}

\section{Список літератури}

[1] Т. А. Семенова, Очистка технологических газов / под ред. Т. А. Семеновой. Москва: Химия, 1977.

[2] Ralph H. Weiland, Nathan A. Hatcher, and Jaime L. Nava, Post-combustion $\mathrm{CO}_{2}$ capture with amino-acid salts. Optimized Gas Treating, Inc. Clarita, OK 74535, USA. [Online]. Available: https://www.protreat.com/files/publications/ 43/Manuscript_CO2_Capture_with_Amino_ Acids.pdf

[3] Аминовая очистка. Россия, 2017. [Электронный ресурс]. Режим доступа: http://gazsurf.com/ru/gazopererabotka/oboru dovanie/modelnyj-ryad/item/aminovayaochistka

[4] А. Л. Концевой, Т. О. Лук’янчук, та С. А. Концевой, "Моделювання очищення газу від оксиду карбону (IV) розчином метилдіетаноламіну", Інтернаука: міжнар. наук. журн., № 15 (55), с. 28-32, 2018.

[5] А. Л. Концевой, Т. О. Лук'янчук, та С. А. Концевой, "Моделювання регенерації розчину метилдіетаноламіну". Інтернаука: міжнар. наук. журн., № 16 (56), c. 32-36, 2018.

[6] Э. Г. Вакк, Г. В. Шуклин, и И. Л. Лейтес, Получение технологического газа для производства аммиака, метанола, водорода и выстих углеводородов. Теоретические основы, технология, катализаторы, оборудование, системы управления: учеб. пособ. Москва, 2011.
[7] М. А. Янковський, I. М. Демиденко, Б. І. Мельников, О. Я. Лобойко, та Г. М. Корона. Технологія аміаку: навч. посіб. Дніпропетровськ: УДХТУ, 2004.

[8] В. П. Семенов, Производство аммиака / под ред. В. П. Семенова. Москва: Химия, 1985.

[9] А. Л. Концевой, та С. А. Концевой, "Моделювання двопотокового очищення газу від оксиду карбону (IV) розчином моноетаноламіну", Вісник Черкаського державного технологічного університету. Технічні науки, № 3, с. 68-75, 2019.

[10] Справочник азотчика: Физикохимические свойства газов и жидкостей. Производство технологических газов. Очистка технологических газов. Синтез аммиака. 2-е изд., перераб., Москва: Химия, 1986.

\section{References}

[1] T. A. Semenova, Process gas cleaning, T. A. Semenova, Ed. Moscow: Himiya, 1977. [in Russian].

[2] Ralph H. Weiland, Nathan A. Hatcher, and Jaime L. Nava, Post-combustion $\mathrm{CO}_{2}$ capture with amino-acid salts. Optimized Gas Treating, Inc. Clarita, OK 74535, USA. [Online]. Available: https://www.protreat.com/files/publications/ 43/Manuscript_CO2_Capture_with_Amino_ Acids.pdf

[3] Amine purification. Russia, 2017. [Online]. Available: http://gazsurf.com/ru/ 
gazopererabotka/oborudovanie/modelnyjryad/item/aminovaya-ochistka/

[4] A. L. Kontsevoi, T. O. Lukianchuk, and S. A. Kontsevoi, "Modeling of gas purification from carbon oxide (IV) with a solution of methyldiethanolamine", Internauka: Int. sci. journ., no. 15 (55), pp. 28-32, 2018 [in Ukrainian].

[5] A. L. Kontsevoi, T. O. Lukianchuk, and S. A. Kontsevoi, " Modeling of regeneration of methyldiethanolamine solution", Internauka: Int. Sci. Journ., no. 16 (56), pp. 32-36, 2018 [in Ukrainian].

[6] E. G. Vakk, G. V. Shuklin, and I. L. Leytes, Production of process gas for the production of ammonia, methanol, hydrogen and higher hydrocarbons. Theoretical foundations, technology, catalysts, equipment, control systems: textbook. Moscow, 2011 [in Russian].
[7] M. A. Yankovskyi,

I. M. Demydenko, B. I. Melnykov, O. Ya. Loboiko, and H. M. Korona, Ammonia technology: textbook. Dnipropetrovsk: UDKhTU, 2004. [in Ukrainian].

[8] V.P. Semenov, Ammonia production, V. P. Semenova, Ed. Moscow: Himiya, 1985 [in Russian].

[9] A. L. Kontsevoi, and S. A. Kontsevoi, "Modeling of two-stream gas purification from carbon oxide (IV) with monoethanolamine solution", Visnyk Cherkaskogo derzhavnogo tehnolohichnogo universytetu, no. 3, pp. 68-75, 2019 [in Ukrainian].

[10] Nitrogen Guide: Physico-chemical properties of gases and liquids. Production of process gases. Process gas cleaning. The synthesis of ammonia. 2nd ed. Moscow: Himiya, 1986 [in Russian].

A. L. Kontsevoi, Ph. D., associate professor, e-mail: kontsev@xtf.kpi.ua

S. A. Kontsevoi, Ph. D., associate professor e-mail: serkon157@ukr.net

Igor Sikorsky Kiev Polytechnic Institute

Peremogy ave., 37, Kyiv, 03056, Ukraine

\section{MODELING OF TWO-FLOW REGENERATION OF MONOETHANOLAMINE SOLUTION}

The simulation object is a two-flow scheme for gas purification from $\mathrm{CO}_{2}$ with monoethanolamine (MEA) solution and with waste solution regeneration in two simultaneously-working recuperators, the productivity of ammonia is 1360 tons per day. Our algorithm considers the temperature fluctuations and component concentrations in liquid phases at different points of the desorber. The algorithm of material and thermal balances calculation is implemented in the Excel. The concentration of $\mathrm{CO}_{2}$ at the outlet of the regenerator is $81.3 \%$. The specific heat consumption for the regeneration of $1 \mathrm{~m}^{3}$ of $\mathrm{CO}_{2}$ is $4.02 \mathrm{MJ}$, which corresponds to industrial data. For kinetic calculation of the desorber, the reference dependences of the equilibrium partial pressure of $\mathrm{CO}_{2}$ over the $20 \%$ MEA solution are approximated, depending on the degree of carbonization and the temperature in the solution. The number of plates in two-section plate desorber is calculated by numerical integration. The control calculation is performed with the following initial data. Gas temperature $-313 \mathrm{~K}$ at the output of the separator; the separator output pressure - 1,7 atm. Gas temperature - $343 \mathrm{~K}$ at the output of the regenerator; the regenerator output pressure - 1,7 atm. The carbonization degree of the MEA solution, kmol per kmol MEA: waste solution - 0,67; roughly recovered solution - 0,35; finely recovered solution-0,1. Temperature, $K$ : on the top plate - 343; output of roughly regenerated solution - 388; output of finely regenerated solution398. The plates' quantity calculation gives 33. This algorithm can be used for analyzing productivity of existing plants, and also will be useful for students' learning of the gas purification process in schemes designing.

Key words: process gas, carbon oxide (IV), monoethanolamine, kinetics and thermodynamics of desorption, plate desorber.

Стаття надійшла 06.11.2019.

Прийнято 28.11.2019

(C) А. Л. Концевой, С. А. Концевой, 2019

DOI: $10.24025 / 2306-4412.4 .2019 .184512$ 